Article

\title{
Children's Engagement with Brands: From Social Media Consumption to Brand Preference and Loyalty
}

\author{
Patricia Núñez-Gómez ${ }^{1 \text {,* }}$, Joaquín Sánchez-Herrera ${ }^{2}$ and Teresa Pintado-Blanco ${ }^{2}$ \\ 1 Department of Applied Communication Sciences, Faculty of Communication Science, \\ Complutense University, 28040 Madrid, Spain \\ 2 Management and Marketing Department, Faculty of Economics \& Business, Complutense University, \\ 28040 Madrid, Spain; joaquins@ucm.es (J.S.-H.); tpintado@ucm.es (T.P.-B.) \\ * Correspondence: pnunezgo@ucm.es
}

Received: 27 August 2020; Accepted: 19 October 2020; Published: 10 November 2020

check for updates

\begin{abstract}
Digital content consumption provides a new scenario for children's relationships with brands. The objective of this research is to study the process by which children interact with social media networks and the effect on brand preference and loyalty generated by this interaction. Specifically, the objectives of this research are focused on empirically verifying the process of consumption, contribution, and creation of children in social networks, and confirm the effect they can have on the relationship between children and brands. A great amount of research has focused on adult consumers and has projected the methodology onto children. This paper will take into account the particularities of children who are one of the most important groups in the purchase decision process of many categories (travel, food, toys, technology, fashion, etc.). For this reason, a theoretical model was built and validated with a sample of boys and girls between the ages of 8 and 14. The results show that the interaction of children with digital media (social networks) has a very important effect on increasing and generating brand preferences and loyalty. Although the effect is general and is not dependent on the age of the child, a more intense effect was observed in children between the ages of 12 and 14 .
\end{abstract}

Keywords: social media; children online behavior; brand preference; brand loyalty; CESBC scale

\section{Introduction}

Children are using social networks (SNs) as part of their interaction with the current context and friends. In that circumstance, brands have the chance to develop different new strategies to get engagement with specific targets in online environments [1].

Children and teens are part of this target audience due to the high use made by them on digital content. In this study, brands are studied in this digital environment and their relationships with children, especially focused on social network brand strategies. How loyalty is developed in this relationship and what factors are being important for generating brand preferences is a goal for this article.

Advance online media branding strategies allow marketers to establish direct, interactive and social relationships between brands and young consumers. In this sense, digital advertising has blurred the boundaries between ads and content. Thus, the Internet has caused young consumers to stop being passive observers and seek their own content [2].

In the case of new advertising formats, this problem is becoming serious related to children. Advertising is permanently creating new ways to attract its public and minors are increasingly more connected to digital platforms. Communication is interactive and bi-directional and has led to the development of a new relationship between brands and children through social media and other 
innovative communication channels that have only recently developed [3]. This fact allows companies to have access to children's data through online profiles or online shopping. It is a fact that a relationship with brands begins at a very early age and that digital media is a contributing factor [4].

Marketers progressively depend more on social and mobile ICT (Information and Communication Technology) channels to market and promote their brands amongst the youth. Furthermore, implementing current and entertaining entertaining content would lead young consumers to share the information with their friends and interact with this same content. In this paper, we will focus on researching the engagement between brands, kids, and their use of social networks as future consumers.

So, the question we are trying to answer is: what role do social networks play in building brand preference and loyalty in children? The specific objectives of this research are focused on empirically verifying the processes of consumption, contribution, and creation by children in social networks, and confirm the effect they can have on the relationship between children and brands.

\section{Literature Review}

As stated before, the evolution of advertising communication has changed brand strategy in this new media and commercial ecosystem in order to interact with its audiences while adapting to new forms of public consumption. New digital media have changed how young consumers are socialized and develop as consumers [2]. These new strategies can generate confusion in minors and produce greater engagement towards them. This is due to ignorance of new formats that are often confused with other types of content. Strategies for delivering advertising as entertainment is something parents are unaware of [5]. Unlike traditional media, online platforms allow children to entertain and play in an experience that lasts longer [6]. Recent studies have highlighted attitude responses in marketing communications on social media [7].

Children are heavy users of social media sites-for example, 66 percent of Spanish children aged 10-15 years have a smartphone, $43 \%$ aged $9-10$ have smartphones, and $25 \%$ of Spanish children visit social networks. Related to teens aged $15-17,97 \%$ have a smartphone device and $50 \%$ have visited a social network. One in three minors visits a social network daily, several times a day, or almost all the time. Forty-five percent of teens between 9 and 16 years old have a social network profile and only $46 \%$ know how to change their profile to private $[8,9]$.

The report "Minors and the Internet: the pending subject of Spanish parents", prepared by the Qustodio security platform, reveals that $4 \%$ of Spanish children between five and eight years old use Instagram, a percentage that rises to $49 \%$ among 12 to 14 -year-olds. The time spent on social networks by Spanish minors between the ages of four and fifteen has grown from $37 \mathrm{~min}$ a day in January 2019 to $83 \mathrm{~min}$ a day in February of this year. According to this study, the social networks most used by children and adolescents have been Instagram, TikTok, and Snapchat.

The Chinese application TikTok has been the one that has shown a greater increment. However, Instagram is still the favorite social network for children under 15 years of age in Spain. This application is used by 47.7 percent of those under this age, while TikTok is used by 37.7 percent and Snapchat by 24.1 percent. In addition, the daily use of the Chinese application has been only 3 min behind that of the YouTube platform, which continues to be the video application most used by minors in Spain. Twenty-three percent of children from 8 to 11 years old, and $74 \%$ from ages 12 to 15 have a profile on social media [10].

Related to brands, $22 \%$ of children between 9 and 12 years old have bought something or have checked the web for prices and $40 \%$ know how to buy using an app.

The use of devices and contents increase with age. At the ages of 3 to 4 years, $1 \%$ have a smartphone, $5 \%$ at the ages of 5 to $7,39 \%$ at the age of 8 to 11 , and $83 \%$ at the ages of 12 to 15 . Tablet usage ranges from $21 \%$ at 3 years old to $55 \%$ at the age of 15 . At 3 to 5 years, $41 \%$ watch TV on other devices, increasing to $68 \%$ at the ages of 12 to 15 . From 3 to 4 years, $48 \%$ use YouTube to watch their favorite content and at the ages of 12 to $15,90 \%$ watch YouTube [11]. Children are also active consumers of audiovisual content. Watching videos is now one of the first activities carried out by young 
children. Children between 3 and 8 years old consider the Internet a source of entertainment [12,13]. Three percent of 5 to 7 -year-olds, the ages where children begin to understand advertising has been studied by different researchers, only are exposed to traditional advertising.

It is necessary to incorporate a new reading of children's advertising in the new digital scenarios (such as SNs), where the commercial strategies of brands can converge with the content of online platforms. In addition, this entertainment content can get the child distracted and provoke confusion to not recognize advertising [14].

Rozendaal et al. [15] verify that between the ages of 8 and 12, children gradually increase their understanding of tactics used by or the intention of the advertiser. The turning point seems to be around the age of 10; however, this may vary depending on the strategy used by the brand. Children at 8 years of age can distinguish between informational content and advertising in its persuasive and suggestive intent. However, it is up to the age of 12 that they show a perception that can be skeptical and critical regarding the intentions of advertising. In this regard, Lawlor et al. [6] refer to the age span of 11 to 16 years as being a reflective stage. Each of these actions can be understood differently according to the age of the child. The most common persuasion techniques used are repetition, product demonstration, popularity among peers, humor, participation of celebrities, and awards [15].

In turn, new strategies are aimed at audiences in a more microsegmented manner and with new approaches that are closer to childlike and adolescent worlds. These new formats make the division between advertising and entertainment unclear [16,17]. Teenagers aged 12 to 15 are not always able to identify, especially in social media, when content seems similar to other content they have seen. In view of this, children will be considered to be followers of the brands that interest them, mainly because they can influence to improve relationships with their peers, especially if these brands are socially relevant. There is an empirical understanding that through social networks, children satisfy identity formation, entertainment and interaction [6], perceived as primary activities in the formation of children as consumers [18].

Children's social media use includes social exchanges to gain valued social rewards for sharing information. In the social interactions of photos, games and images, brands have a presence through characters or profile images [6]. In children, these social interactions of marketing content end up spreading among the same users.

Thus, in social media the content that the user generates with the brand reinforces the relationship between brands and their consumers, with which these media have a considerable influence on the relationship between each other [19]. In this regard, the term consumer brand engagement (CBE) has been addressed by different researchers (Figure 1). Hollebeek et al. [20] believe that this concept reflects the nature of interactive characteristics of consumers with brands more adequately than the term involvement, which is a more traditional concept [21]. The term implies a cognitive, emotional, and behavioral activity related to the brand, which is positively validated by the consumer during interactions that he or she makes with it.

Although online ads are distinguished by a box with the word "advertising", only a minority of 8 to 11 -year-olds ( $28 \%$ ) and 12 to 15 -year-olds (43\%) can correctly identify sponsored links as advertising [22]. This topic has been a focus of interest [23,24] for researchers to determine whether adequate advertising literacy could mitigate persuasive effects caused by the brands. However, this has not been confirmed and there is research that shows that this may not be the case [25]. Children between the ages of 10 to 12 develop an understanding of the persuasive aspect of advertising. They understand that brands can influence a person's intention to purchase and that they have the ability to cause changes in thinking and attitude. This goes beyond simply understanding that advertisers intend to sell; it indicates that young people understand that advertising can change purchasing behavior through a change in thinking and attitudes [15]. This is also the age where they perceive how tactics employed by advertisers can be used to change their attitudes. The age of 10 is crucial in understanding the advertiser's strategies. In this sense, other researchers agree that, at this age, children also begin to 
think about brands on a conceptual level rather than a superficial level. They also think of brands on a more abstract level by understanding how the advertising can be used to impress third parties.

The persuasive effect of advertising consists, among other intentions, of trying to indirectly influence a change in one's beliefs and desires towards a product. The latter is understood by children roughly by the age of 10 [15]. Regardless of this understanding, there is nothing that proves that this knowledge helps children defend themselves from the effects of advertising. Even children at the age of 12 may not be able to understand how to apply this knowledge. Not only do rational responses count but emotional ones as well when testing the effectiveness of advertising. Cognitive defenses alone do not guarantee one to be immune to the effects of advertising and cognitive reasoning can be neutralized by a very emotional advertisement. In the case of minors, the relationship established by the brand during the time one begins to create personal identity relationships is very important because the brand can influence the concept of oneself. At this time, a projective mechanism is established and it is possible to establish whether this relationship between the young person and the brand is consistent [4].

The emergence of social media has changed the way consumers connect with brands. Social media in this context is interesting because it has allowed the grouping of audiences around brands, which produces communities that have common identities. This serves brands by allowing them to produce a greater exchange with consumers. At an early age (7 to 8 years old), children make a number of connections with brands and their identities based on specific associations. In adolescence, these connections increase as brands become more related to the concept of oneself. The brand has its own personality and characteristics that are similar to the adolescent's way of life or reference group [26]. In these communities, teenagers participate actively in the creation of content if the brand is able to get their attention.

By this time, the mobile becomes the star device. Since most of the advertising agencies have a digital strategy and most of the children engage in activities on social media, it is important to measure the activities of the young consumer in social media and their relationship with the brand.

The ability that some young people are demonstrating to manage content and followers is turning some minors into an object of interest for brands. The phenomenon of the smaller "YouTuber" is fascinating as an infinite source of content innovation and test space for new communicative styles. YouTube has allowed children to become creators, producers, and broadcasters of content from their phones. On the other hand, it also generates urgent regulatory implications and the need for guidance for the strategic and safe performance of brands. In the case of new formats, different strategies are being created to achieve these objectives. Advergames, branded websites, entertainment paid for by brands, and other formats have saturated the children's environment and have dissolved boundaries between advertising and other media content, making it difficult to understand $[27,28]$. These techniques are very interactive, making children feel immersed in new content and they are encouraged to collaborate actively [25]. Social networks allow kids to share opinions and brand recommendations. Persuasive and suggestive advertising designed as entertainment leads to minimizing the barriers of skepticism of children and young people, which places them in an environment with greater vulnerability to brand content [2]. Brands develop different strategies to look like "persons" in social networks and in this way is easier to connect with kids, starting a relationship. Brands through social networks are more anonymous and can build more emotional patterns encouraging kids to reveal more about themselves.

Within the digital context, entertainment goals and social goals occur in interaction. Children participate in social media to be able to interact with their friends and share both content and ideas in which both entertainment and identity are given. There are several behaviors that children use for their interactions on social media, such as the buttons on social media to react or support content, follow, share, as well as comment on different kinds of content. In particular, children between 12 and 14 years old consume and share content [29], even creating a profile on a social media can cause children to publicly position themselves in their brand predilections [6]. The advergames, or games designed by a brand, as well as the questionnaires that these applications carry are part of the strategies 
that brand marketers produce to get closer to the youngest. The blurring of the boundaries between brand advertising and entertainment in games and social media has caused children, unaware of this situation, to actively participate in brand content. The truth is that the intention of the specialists is to involve the consumer, in such a way that the interactions influence children's learning, conditioning their entertainment objectives and their social objectives in social media. As a result, the digital context causes brands to spread and amplify content that is easy to share. As soon as the content of the brand generates interest and entertainment, it will be shared by children on the networks.

Based on these previous investigations, the working hypotheses proposed are the following:

Hypothesis 1 (H1). The consumption of digital content has a positive and significant effect on a child's participation in the valuation of said content.

Hypothesis 2 (H2). The participation of a child in the assessment of digital content has a positive and significant effect on the creation of new content.

Hypothesis 3 (H3). The creation of new digital content by the child has a positive and significant effect on brand preference.

Hypothesis 4 (H4). The creation of new digital content by the child has a positive and significant effect on brand loyalty.

Hypothesis 5 (H5). Brand preference has a positive and significant effect on the generation of loyalty.

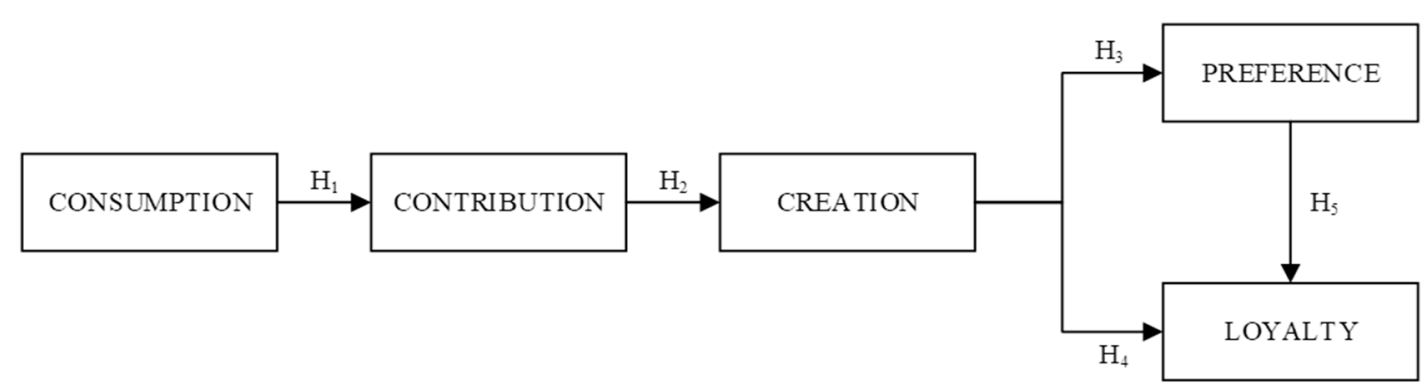

Figure 1. Theoretical Model.

\section{Methodology}

Cognitive, emotional, and behavioral aspects can be observed in the relationship between consumers and brands. Brodie et al. [30] define customer engagement as a psychological state that occurs through the interaction and co-creativity of the client's experience with an agent or object (brand). To measure this relationship, Hollebeek et al. [20] proposed a scale that adds value, [31] but it has not been validated to work with minors.

Other precedents are also found in the Consumers Online Brand Related Activities framework (COBRA model) [32]. The COBRA model measures three levels of engagement, which are consumption, contribution, and creation; however, it has not been applied to children. As the advertising environment has changed very fast to online content, the research tries to improve a model to adapt this scale to children and their digital consumption with brands.

\subsection{Sampling and Data Collection}

The proposed theoretical model consists of a sample of children, randomly selected, from eleven schools within different Spanish provinces. Due to the age of the children, parental consent was asked for. The final sample consisted of 568 individuals. Questionnaires that presented inconsistencies or blank answers were excluded, providing a $4.1 \%$ sample error for $p=q=0.5$. The profile of the participants is shown in Table 1. 
Table 1. Descriptive Analysis.

\begin{tabular}{ccc}
\hline & Frequency & Percentages \\
\hline Age & & \\
Eight & 25 & 4.40 \\
Nine & 46 & 8.10 \\
Ten & 62 & 10.92 \\
Eleven & 178 & 31.34 \\
Twelve & 184 & 32.39 \\
Thirteen & 57 & 10.04 \\
Fourteen & 16 & 2.82 \\
Sum & 568 & 100.00 \\
Gender & & \\
Boys & 262 & 46.13 \\
Girls & 306 & 53.87 \\
Sum & 568 & 100.00 \\
\hline
\end{tabular}

Data collection was done through a direct survey, which consisted of a structured questionnaire containing the Consumer's Engagement with Social Media Brand-Related Content (CESBC) scale as basic constructs [33], and the remaining necessary constructs for the estimation of the proposed theoretical model. The original scale was not adapted to a child's language, so it was decided to pretest the questionnaire in order to verify that the concepts included were understood without difficulty. Four group meetings were held with nine participants in each group and each meeting lasted approximately $50 \mathrm{~min}$. As a result, some discrepancies were found between the language used on the CESBC scale and terms children used to refer to the main concepts. For example, children did not distinguish between "tracking" a brand on social media and "subscribing" to that brand's channel. Similarly, the very concept of social media was confusing to them. For most of the participants, there were no differences between the Internet and "social media". Oftentimes, "social media" was only identified with YouTube while other social media sites such as Facebook, Twitter, Instagram, etc. were completely unnoticed by children and they had no relationship with them. This was the same for other online interaction tools such as blogs, forums, etc. Other concepts present in the original scale, such as "like" or "upload/upload videos", were understood perfectly by the children. Based on these results, modifications were made to some of the original items used in the questionnaire. For example, instead of "I comment on the videos ... " (first item of the "Contribution" construct of the original CESBC scale), the wording was changed to a more colloquial form, such as "I write things about the videos ... ". In other cases, items referred exclusively to forums or blogs were removed from the scale because they were not understood by the participants.

\subsection{Measures Development}

Latent variables used for the estimation of the model were measured by sets of items, which were evaluated through a five-point Likert scale ranging from "totally disagree" to "totally agree". They were inversely coded when it was necessary to do so. So that the children did not have difficulty understanding the metric sense of the items, a graphic scale based on emoticons was used. This did not present problems or interpretation biases in the pilot tests performed. Following the CESBC scale proposed by Schivinski et al. [33], the "Consumption" dimension was constructed from a set of three items: "I like to read on the Internet what's coming out from my favorite brands", "I like to see photos on the Internet of my favorite brands", and "I like to follow my favorite brands on social media". "Contribution" consisted of two items: "I like to share videos of my favorite brands on the Internet", and "I click 'like' for videos where my favorite brands appear". Finally, the "Creation" factor was formed from three items: "I like to be the first to write things about my favorite brands on the Internet", "I like to upload photos or drawings of my favorite brands on the Internet", and "I like to write things on the Internet about my favorite brands". The "Brand Preference" construct was measured following 
Yoo and Donthu [34] as well as Sirgy et al. [35] using the items "I prefer my favorite brands over any other brand" and "If my favorite brand costs a lot of money, I ask for a different brand". "Loyalty" was built from the modified scale of Yoo and Donthu [34] using the items "Even if there were other similar brands, I would always wear my favorite brands" and "If I could, I would always ask for the same brands".

For the estimation of the structural model and measurement model, an analysis of extreme cases was made. The multivariate normality hypothesis was confirmed. Although there are more tolerant estimates with respect to this requirement, such is the case of asymptotically distribution free (ADF) [36,37], they can, however, be problematic for the estimation of parameters. The Mahalanobis distance [38] has been used to locate extreme multivariate cases. As a consequence of the analysis, 12 cases have been removed from the sample because they are far from the central tendency of the multivariate values. After this process, the data does not have anomalies that could cause an alteration in the estimation of structural parameters. For the normality analysis, the Mardia coefficient has been used [39]. The kurtosis value taken from all the variables did not have high values, which facilitates the use of the theoretical model without problems related to the lack of multivariate normality. In any case, the proposed model was estimated with additional bootstrapping procedures [40] to guarantee the reliability of the parameters obtained. Regarding lost values, despite not assuming a significant percentage of the sample (9.4\%), it was decided to use an expectation-maximization (EM) allocation algorithm [41] to avoid losing sample power. In any case, the estimation of the proposed theoretical model did not show significant differences with the elimination of lost values from the database.

\section{Results}

The estimation of the model and the interpretation of the results were carried out following the classical sequential process in the models of structural equations. In the first place, the reliability and validity of the measurement model were analyzed in order to estimate the structural model and contrast the hypotheses.

\subsection{Measurement Model Evaluation}

\subsubsection{Reliability}

In all cases, the Cronbach alpha statistic scores [42] were higher than the established standard limits (Table 2) while the results of the confirmatory analysis showed the expected factor structure consistent with the findings of Schivinski et al. [33]. In this sense, the model did not pose internal validity problems.

Table 2. Chronbach's Alpha and 0.95 Confident Intervals.

\begin{tabular}{ccccc}
\hline Constructs & Alpha & Lower & Upper & Std. Error \\
\hline Consumption & 0.85 & 0.83 & 0.87 & 0.011 \\
Contribution & 0.83 & 0.80 & 0.86 & 0.012 \\
Creation & 0.83 & 0.81 & 0.86 & 0.011 \\
Preference & 0.93 & 0.91 & 0.94 & 0.006 \\
Loyalty & 0.90 & 0.88 & 0.92 & 0.008 \\
\hline
\end{tabular}

Regarding composite reliability, none of the calculated indicators are less than 0.7 , so it can be said that there are no reliability problems in the estimates [43] (see Table 3).

\subsubsection{Validity}

The results obtained through the calculation of the average variance extracted (AVE) show values above 0.5 , so the model does not present convergent validity problems [44]. In addition, all factor loads of the measurement model are significant and are above 0.5 (see Table 3). 
Table 3. Factor Loadings for the Items and Composite Reliability.

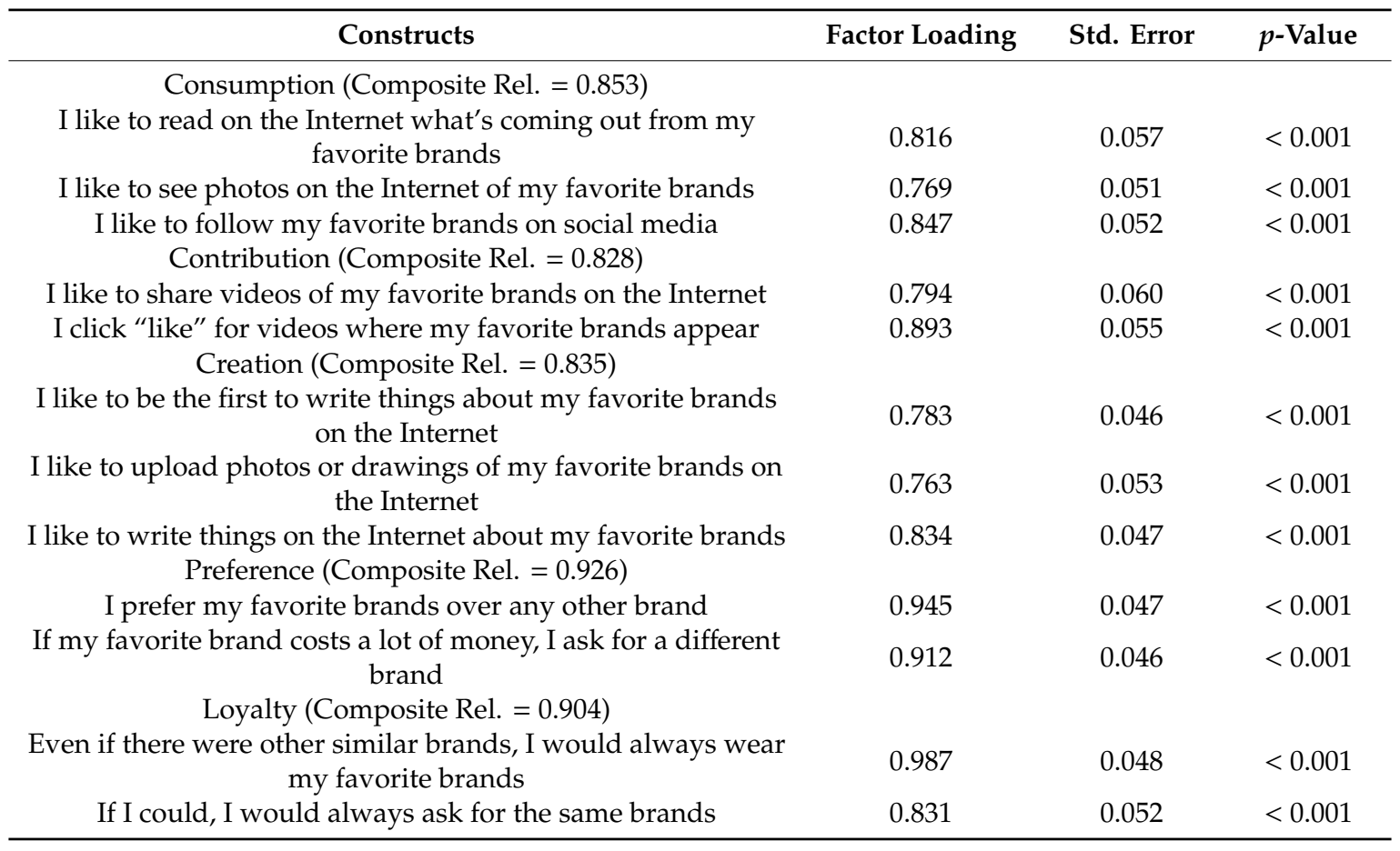

The following indicators were used to assess the validity of the construct: (i) the statistic $\chi^{2}$ and its significance value, (ii) standardized root mean square residual (SRMR), (iii) normed fit index (NFI), (iv) root mean square error of approximation (RMSEA) and its confidence interval, and (v) comparative fit index (CFI) [37]. The only test of significance is the chi-square statistic, however, it is susceptible to infringement of the assumptions of normality and of the sample conditions. To compare the covariance matrix of the model with the covariance matrix of the sample, the SRMR and RMSEA indices are descriptive indicators of goodness of fit. As for CFI and NFI, they are comparisons with a model in which all the variances are zero.

The Table 4 shows the fit indices and also the adjusted goodness of fit index (AGFI), which takes into account the complexity of the model and would be equivalent to the adjusted coefficient in linear models. The other index in the table is the goodness-of-fit index (GFI), which is similar to the coefficient of determination in linear regression. Except for the chi-square statistic $\left(\chi^{2}=128.45 ; d f=49 ; p<0.001\right)$, the other indicators are within the accepted parameters as good or very good. Given the limitations of this indicator to assess the goodness of fit of a structural model [45-47], the results obtained can be trusted.

Table 4. Fit Measures.

\begin{tabular}{cccc}
\hline Index & Value & CI (Lower) & CI (Upper) \\
\hline RMSEA & 0.054 & 0.042 & 0.065 \\
SRMR & 0.052 & & \\
NFI & 0.969 & & \\
CFI & 0.980 & & \\
GFI & 0.964 & & \\
AGFI & 0.942 & & \\
\hline
\end{tabular}

Abbreviations: Root mean square error of approximation (RMSEA), standardized root mean square residual (SRMR), normed fit index (NFI), comparative fit index (CFI), goodness-of-fit index (GFI), adjusted goodness-of-fit index (AGFI). 
Finally, discriminant validity was assessed by the matrix formed by the square root of the mean variance extracted ( $\sqrt{ } \mathrm{AVE}$ ) on the diagonal and the correlations between constructs outside the diagonal [44]. In all cases, the values of the square root of AVE are greater than the correlations and, therefore, there are no problems related with validity (see Table 5).

Table 5. Discriminant Validity Matrix.

\begin{tabular}{cccccc}
\hline & Consumption & Contribution & Creation & Preference & Loyalty \\
\hline Consumption & 0.813 & & & & \\
Contribution & 0.738 & 0.843 & & & \\
Creation & 0.629 & 0.691 & 0.792 & & \\
Preference & 0.289 & 0.33 & 0.23 & 0.929 & \\
Loyalty & 0.191 & 0.34 & 0.337 & 0.535 & 0.909 \\
\hline
\end{tabular}

Note: Square root of average variance extracted (AVE) on the matrix diagonal.

Fornell and Larcker's procedure [44], although being the most popular, has received some criticism for its tendency to overestimate the value of factor loads $[48,49]$. Therefore, the discriminant validity of the model has been evaluated using the heterotrait-monotrait ratio (HTMT) method [48]. In this case, the average correlation between the indicators is evaluated through the set of constructs in relation to the correlation between indicators within the same construct [48]. Although some researchers propose a more demanding limit, the estimated values can be interpreted as inter-construct correlations and are considered adequate if they do not exceed the unit. For example, Kline [50] proposes a limit value of 0.85, while Teo, Tsai, and Yang [51] put it at 0.9. Table 6 shows the result of the HTMT estimate, where the highest value between constructs is 0.73 . Therefore, it can be affirmed that the model does not present problems associated with a lack of discriminant validity.

Table 6. Heterotrait-Monotrait Ratio (HTMT).

\begin{tabular}{cccccc}
\hline & Consumption & Contribution & Creation & Preference & Loyalty \\
\hline Consumption & 1.000 & & & & \\
Contribution & 0.735 & 1.000 & & & \\
Creation & 0.624 & 0.691 & 1.000 & & \\
Preference & 0.281 & 0.338 & 0.231 & 1.000 & \\
Loyalty & 0.214 & 0.369 & 0.336 & 0.541 & 1.000 \\
\hline
\end{tabular}

\subsection{Hypothesis Testing}

The hypotheses of this investigation attempt to verify the sequential process of online interaction of children proposed by Schivinski et al. [33] and, where appropriate, analyze the effect it has on two key aspects in the relationship between consumers and brands: preference and loyalty. To test these hypotheses, a model of structural equations was used with the estimated values shown in Table 7.

Table 7. Summary of SEM (Search Engine Marketing) Results.

\begin{tabular}{cccccccc}
\hline & Hypotheses & & & Estimate (Std.) & Std. Error & Critical Value & $p$-Value \\
\hline H1 & Consumption & $\rightarrow$ & Contribution & 0.762 & 0.095 & 12.369 & $<0.001$ \\
H2 & Contribution & $\rightarrow$ & Creation & 0.729 & 0.061 & 11.225 & $<0.001$ \\
H3 & Creation & $\rightarrow$ & Preference & 0.265 & 0.034 & 5.481 & $<0.001$ \\
H4 & Creation & $\rightarrow$ & Loyalty & 0.228 & 0.036 & 5.343 & $<0.001$ \\
H5 & Preference & $\rightarrow$ & Loyalty & 0.478 & 0.055 & 10.274 & $<0.001$ \\
\hline
\end{tabular}

All coefficients have the expected signs according to the hypotheses proposed and are statistically significant $(p<0.001)$. The sequential process proposed by Schivinski et al. [33] is true for children between the ages of 8 and 14, showing positive parameters in the three phases of online interaction. 
The propensity to participate in social media is positively and directly related to the consumption of content related to brands (H1: "Consumption" $\rightarrow$ "Contribution"). Similarly, the greater the contribution of individuals in social media, sharing content or evaluating the contents or contributions of other users, the greater the propensity to create new content and take the initiative in relation to children's favorite brands (H2: "Contribution" $\rightarrow$ "Creation").

When users have reached the third level of online interaction ("Creation"), it is interesting to note the effect it can have on brand loyalty and preference. According to the results obtained, the preference for a brand is positive and directly related to the creation of content for that brand (H3: "Creation" $\rightarrow$ "Preference"). Similarly, online interaction based on content creation has a positive and significant effect on brand loyalty (H4: "Creation" $\rightarrow$ "Loyalty"). In addition, our hypotheses established a direct effect of brand preference, which also yielded positive and significant values (H5: "Preference" $\rightarrow$ "Loyalty"). This relationship implies an indirect effect of the creation of content on brand loyalty through preference ("Creation" $\rightarrow$ "Preference" $\rightarrow$ "Loyalty").

Table 8 shows the indirect and total effects of this specification and the proportion of the indirect effect. According to these results, the indirect effect of content creation on loyalty is positive and significant and, in addition to the direct effect previously estimated, the total effect of creation on loyalty is 0.355 . The indirect effect represents $35.7 \%$ of the total effect of this relationship.

Table 8. Indirect, Total, and Proportion Effects of Creation on Loyalty.

\begin{tabular}{ccccc}
\hline Effect & Estimate (Std.) & Std. Error & Critical Value & $p$-Value \\
\hline Indirect effect & 0.127 & 0.033 & 5.222 & $<0.001$ \\
Total effect & 0.355 & 0.062 & 7.813 & $<0.001$ \\
Proportion effect & 0.357 & 0.063 & 5.629 & $<0.001$ \\
\hline
\end{tabular}

According to these results, online interaction with brands has a positive effect on the preference and loyalty of those brands, which is manifested from very early ages. Indirectly, the greater the consumption of the contents of a brand seen in social media, the greater the involvement of the child with that brand, strengthening their preference and establishing links that can intentionally last over time. These results are similar to other articles. Marketing in the digital environment strengthens brand relationships through interaction with young consumers $[3,52,53]$. In some cases, the comments generated about the brand are proof of the strong involvement it has with consumers who publish images and share personal information about themselves and their closest circle [2].

\subsection{Multigroup Analysis}

Depending on the results of some of the most recent research on the behavior of children and adolescents, there may be significant differences in behavior before and after the age of $11[54,55]$. Based on this, the models for two age groups estimated are (i) children between the ages of 8 and 11 and (ii) children between the ages of 12 and 14. The estimation of the model parameters for the two age groups is shown in Table 9, in which all the coefficients are significant but with differences in magnitude between groups. For example, the effect of consumption on contribution is 0.671 for the group of children between 8 and 11 years and 0.836 for the group between 12 and 14 years. To find out if these discrepancies are sufficiently important, a difference test was conducted. The results showed that only two of the five pairs of parameters have statistically significant differences. 
Table 9. Parameter Estimates by Group.

\begin{tabular}{ccccccccc}
\hline Construct & & Construct & Group & Estimate (Std.) & Std. Error & Cr. Value & $p$-Value & Sig. \\
\hline Consumption & $\rightarrow$ & Contribution & From 8 to 11 & 0.671 & 0.063 & 9.972 & $<0.001$ & $* * *$ \\
Consumption & $\rightarrow$ & Contribution & From 12 to 14 & 0.836 & 0.062 & 13.738 & $<0.001$ & $* * *$ \\
Contribution & $\rightarrow$ & Creation & From 8 to 11 & 0.659 & 0.050 & 9.426 & $<0.001$ & $* * *$ \\
Contribution & $\rightarrow$ & Creation & From 12 to 14 & 0.784 & 0.049 & 12.467 & $<0.001$ & $* * *$ \\
Creation & $\rightarrow$ & Preference & From 8 to 11 & 0.165 & 0.099 & 2.353 & 0.0186 & $* *$ \\
Creation & $\rightarrow$ & Preference & From 12 to 14 & 0.336 & 0.077 & 5.429 & $<0.001$ & $* * *$ \\
Creation & $\rightarrow$ & Loyalty & From 8 to 11 & 0.219 & 0.085 & 3.725 & $<0.001$ & $* * *$ \\
Creation & $\rightarrow$ & Loyalty & From 12 to 14 & 0.229 & 0.075 & 4.064 & $<0.001$ & $* * *$ \\
Preference & $\rightarrow$ & Loyalty & From 8 to 11 & 0.523 & 0.058 & 9.162 & $<0.001$ & $* * *$ \\
Preference & $\rightarrow$ & Loyalty & From 12 to 14 & 0.446 & 0.059 & 8.062 & $<0.001$ & $* * *$ \\
\hline
\end{tabular}

Note: ${ }^{*} p<0.1 ;{ }^{* *} p<0.05 ;{ }^{* * *} p<0.01$.

Estimates in Table 10 show that age groups differ in the magnitude of the effect that content consumption has on contribution as well as creation. Thus, older children (12 to 14 years old) show greater effects than younger children, suggesting there is a greater propensity in older children to interact with brands. However, this effect occurs only in the online interaction process. The model does not show significant differences in the effects that online interaction with brands have on preference and loyalty. Therefore, although there are differences in the way children relate to brands on social media, how that interaction affects brand preference or loyalty remains unchanged. In this sense, children between the ages of 8 and 11 are neither more nor less sensitive to the process of preference formation and brand loyalty than children aged 12 to 14 .

Table 10. Test of Differences between Groups.

\begin{tabular}{cccccccc}
\hline Construct & & Construct & Estimate (Std.) & Std. Error & Cr. Value & $p$-Value & Sig. \\
\hline Consumption & $\rightarrow$ & Contribution & -0.165 & 0.077 & -2.956 & $<0.001$ & $* * *$ \\
Contribution & $\rightarrow$ & Creation & -0.125 & 0.062 & -2.144 & 0.032 & $* *$ \\
Creation & $\rightarrow$ & Preference & -0.171 & 0.124 & -1.469 & 0.1417 \\
Creation & $\rightarrow$ & Loyalty & -0.009 & 0.112 & 0.113 & 0.9098 \\
Preference & $\rightarrow$ & Loyalty & 0.077 & 0.081 & 0.673 & 0.5008 \\
\hline
\end{tabular}

Note: ${ }^{*} p<0.1 ;{ }^{* *} p<0.05 ;{ }^{* * *} p<0.01$

\section{Discussion}

This research explores the novel aspect of the creation of content by children, the opportunity to contribute to the construction of the brand, and how that leads to a different relationship.

Working with minors leads one to consider whether this joint construction produces greater engagement with advertising and, as a consequence, greater loyalty and greater appreciation of the brand. As a result of consumers being able to contribute content, brands acquire information from their public instantly, however, this raises different questions since the demographic is children.

In this study, the age of the participants makes the difference in relation to the same studies related to adults. The development process of the personality means then the instrument must be adapted and the persuasion comprehension process implies different cognitive steps than similar studies conducted previously in adult populations and other countries. The case of children is difficult due to the consent of use of social networks at these ages, even when they use it. It makes it difficult to ask for it in quantitative surveys.

The innovation of the study is to adapt this model thought for adults and design the language for children and different measures. It is important to highlight that the study mixes the research between young consumers and social networking behavior.

The main purpose of this work is to study the relationship between children and digital media and the effect caused by their online interaction with brands. Until now, studies have addressed partial aspects of the process; however, this research validates for the first time the sequential process in 
children and links it to the generation of positive results for brands (preference and loyalty). The results obtained support the proposed theoretical model in which the consumption of digital content leads to an increase in the child's participation in the evaluation of said content, which, in turn, positively influences the creation of new content. The child's interaction with digital media increases his or her preference for brands and also generates an increase in loyalty to them. This process, however, occurs with greater intensity among children between the ages of 12 and 14 .

Research about the role of the brands has found that the intention of children to offer recommendations is due to the level of participation that they have in a brand network as well as the feelings they experience [56].

Children stablish relationships with brands that can be positive or negative depending on the terms in which this relationship is characterized. If the relationship is positive, the children will play an active role [4].

In digital environments, it is easier to provoke interactions between brands and consumers, creating interactive media and contacts, creating online games, entertainment, etc. that encourage sharing among friends, even in real time. Using influencers on social networks, especially for young people, makes the brand more truthful. By sharing the brand's comments, the same child is a prescriber towards their group and the brand becomes a reference. Greater regulation is needed by states and companies to ensure parental consent and the proper training of minors, for example, knowing that, by giving consent to use cookies, they are forming part of the marketing of a company.

According to these findings, brands should act responsibly in their use of digital media when they target children and contribute in any way possible to the generation of content that does not violate their rights. As with conventional communication, brands should safeguard fundamental principles of respect, freedom, and the dignity of the child and avoid indiscriminate generation of commercial messages that do not take into account the special characteristics of this group of consumers.

It is necessary that these ages and their characteristics be known in a deeper way and they are taken into account from their opinions, starting from a non-adult point of view. This will make brands build in a more responsible and transparent way, building a relationship of honesty with the public. Brands that do not work in this sense will not survive, since the public demands transparency and connection with society.

That brands help to build better social well-being and that they help develop their growth and values is required by these audiences. If they do not comply, they will abandon them.

The loyalty they develop towards brands can be used to learn proper techniques, lifestyles, and responsibilities. Brands have a great opportunity there. They should be considered part of the system; consumption is not only buying, it is the acquisition of symbolic values that build their world and that will make them better adults in the future.

When they create content, they add value to the brand and it will benefit it, so their language must be appropriate. They must understand your concerns and help build a better world.

Therefore, communication must be credible and real, with behaviors linked to society, with real events. Thus, the brand will really continue in their life when they grow up.

In that listening they should adapt to their channels and, according to their age, help them define what is advertising and what is not, both in the content and in the format. They should take care of them when they are broadcasting epublicity and in the channels carried out by minor influencers, since, as we have seen, this type of communication makes the brand more credible. They should also clarify misunderstood concepts and use more appropriate terms or icons that help and clarify what is advertised and its intention.

Although the contribution of this work reveals new ways of understanding children's relationship with digital media and brands, it would be desirable to increase the scope of these findings by differentiating between product categories (sports brands, toys, food, etc.) and to explore possible differences between them. In addition, it would be interesting to extend the scope of the sample to 
other countries. By doing so, comparisons could be made about the behavior of children in different cultural settings as well as the effect that different educational systems may have on such behavior.

It would also be advisable to carry out studies that compare whether the relationship varies depending on different sectors as well as research different strategies used. There is also a gap for future research to identify if online strategies used are different from those of traditional advertising or if the persuasive elements are repeated. In this sense, analyzing new formats would give clues to see where the greatest engagement occurs. Consequently, it is essential to highlight and know the way in which young consumers of digital content observe SNs, as well as the causes that intervene in their attitudes, because this improves ICT strategies and defines online marketing communications.

In this sense, Schivinski and Dabrowski [57] findings revealed that both user and brand communications from organizational social media positively influenced awareness. Labrecque's [58] defined that the brand's interactions in different areas of social media had a positive impact on cognitive responses. In the same way, this study yielded positive cognitive attitudinal responses in relation to the interaction of the brand in social media.

Brands and their organizations constantly need to deliver accurate and current content to children and teens, who can capture information immediately, but also quickly detach from it if there is no stimulation of commitment [7]. This is the point companies are using for marketing engagement.

Consumers with greater activity in the digital environment were more likely to use commercial content online to support their purchases. We have to be aware of this point. To a large extent, young people have become immune to traditional marketing; consequently, many media outlets have seen their advertising revenue decline. On the other hand, interactive digital advertising is more resistant to the interests of young people, as well as to market conditions, with which they have experienced growth during the last ten years $[59,60]$.

Among the limitations of the study is the variety of social media that are used by these generations which could be observed separately. This study did not take into account analyzing a specific brand, on the contrary, it examined marketing communications in social media in a general way, which may be a way for further investigation.

It would be convenient to complete this study qualitatively to measure the emotional part that is part of the process in this relationship.

Delving further into the gender roles of advertising aimed at these generations would be interesting since we could discover if this aspect has evolved, as well as ask them if they consider these roles represent them.

It would be interesting to evaluate the different formats separately, since a marketing influencer is not the same as a branded content, for example, even if both communicate through social networks.

This study could be applied to each product category to see which strategies are more interesting for these ages and whether it depends on the sector or the type of formats used.

In subsequent studies, the characteristics of each social network and the type of advertising distributed should also be explored.

Related to the social impact of the study, this research was designed inside different projects performed by the Digital Chair for Children and Teens. This Chair works with different schools in Spain, and it is part of different school programs to make children more critical of the new advertising formats. In this sense, the results of the research also provide to the brands new responsibilities when they plan their messages.

\section{Conclusions}

The advent of the media has led specialists to communicate with young consumers about their products; indeed, the influence of communication between consumers has grown exponentially in the market.

There are no organizations that can grow without marketing strategies that allow their brands to provoke favorable attitudinal responses among users, and that can culminate in the propensity on 
the part of the consumer to buy the brand. To this point, it is necessary to improve social and legal regulation about marketing content to help children and families to distinguish advertising content.

This study concluded that marketing communications on virtual platforms and especially on social media affect all attitudinal elements. Therefore, the greater the consumption of the contents of a brand seen on social media, the greater the involvement of the child with that brand, strengthening their preference and establishing links that can intentionally last over time building loyalty. These results could provide the basis for further studies focused on the analysis of cultural differences, the impact of advertising on choice behavior, or children's ability to influence other children (word of mouth).

Author Contributions: T.P.-B. and J.S.-H. have carried out the data preparation and cleaning, the descriptive analysis of the sample and the estimation of the empirical model. P.N.-G. has developed the theorical framework and pretest the questionnaire. She carried out the discussion and conclusions. All authors have read and agreed to the published version of the manuscript.

Funding: This research received no external funding.

Conflicts of Interest: The authors declare no conflict of interest.

\section{References}

1. Malthouse, E.; Hofacker, C. Looking back and looking forward with interactive marketing. J. Interact. Mark. 2010, 24, 181-184. [CrossRef]

2. Confos, N.; Davis, T. Young consumer brand relationship building potential using digital marketing. Eur. J. Mark. 2016, 50, 1993-2017. [CrossRef]

3. Montgomery, K.; Chester, J. Digital Food Marketing to Children and Adolescents: Problematic Practices and Policy Interventions; Public Health Law Policy: Oakland, CA, USA, October 2011.

4. López, A.; Rodríguez, R. Children and their brands: How young consumers relate to brands. J. Consum. Mark. 2018, 35, 130-142. [CrossRef]

5. Kelly, B.; Vandevijvere, S.; Freeman, B.; Jenkin, G. New media but same old tricks: Food marketing to children in the digital age. Curr. Obes. Rep. 2015, 4, 37-45. [CrossRef]

6. Lawlor, M.; Dunne, Á.; Rowley, J. Young consumers' brand communications literacy in a social networking site context. Eur. J. Mark. 2016, 50, 2018-2040. [CrossRef]

7. Duffet, R. Influence of social media marketing communications on young consumers' attitudes. Young Consum. 2017, 18, 19-39. [CrossRef]

8. Instituto Nacional de Estadística (INE). 2019. Available online: https://www.ine.es/ (accessed on 4 May 2020).

9. Eukids Online 2020. Informe de Actividades, Mediación, Oportunidades y Riesgos Online de los Menores. Available online: https:/www.is4k.es/de-utilidad/recursos/informe-de-actividades-mediacionoportunidades-y-riesgos-online-de-los-menores (accessed on 6 June 2020).

10. Qustodio. Apps and Digital Natives: The New Normal. Qustodio Annual Report on Children's Digital Habits. 2020. Available online: https:/qweb.cdn.prismic.io/qweb/e59c2e0f-ef4f-4598-b330-10c430e2ec71_ Qustodio+2020+Annual+Report+on+Children\%27s+Digital+Habits.pdf (accessed on 6 June 2020).

11. Eukids online. The Better Internet for Kids Policy Map: Implementing the European Strategy for a Better Internet for Children in European Member States. Available online: https://www.lse.ac.uk/ media-and-communications/research/research-projects/eu-kids-online/reports-and-findings (accessed on 7 November 2019).

12. Holloway, D.; Green, L.; Livingstone, S. Zero to Eight. Young Children and Their Internet Use; EU Kids Online: London, UK, 2013.

13. Blackwell, C.; Lauricella, A.; Wartella, E. Factors influencing digital technology use in early childhood education. Comput. Educ. 2014, 77, 82-90. [CrossRef]

14. Shin, W.; Huh, J.; Faber, R.J. Developmental antecedents to children's responses to online advertising. Int. J. Advert. 2012, 31, 719-740. [CrossRef]

15. Rozendaal, E.; Lapierre, M.A.; Van Reijmersdal, E.A.; Buijzen, M. Reconsidering advertising literacy as a defense against advertising effects. Psychol. Media 2011, 14, 333-354. [CrossRef]

16. Moore, E. Children and the changing world of advertising. J. Bus. Ethics 2004, 52, 161-167. [CrossRef] 
17. Calvert, S.L. Children as consumers: Advertising and marketing. Future Child. 2008, 18, 205-234. [CrossRef] [PubMed]

18. Kennedy, A.; Jones, K.; Williams, J. Children as vulnerable consumers in online environments. J. Consum. Aff. 2019, 53, 1478-1506. [CrossRef]

19. Hudson, S.; Huang, L.; Roth, M.S.; Madden, T.J. The Influence of social media interactions on consumer-brand relationships: A three-country study of brand perceptions and marketing behaviors. Int. J. Res. Mark. 2016, 33, 27-41. [CrossRef]

20. Hollenbeek, L.; Glynn, M.; Brodie, R. Consumer brand engagement in social media: Conceptualization, scale development and validation. J. Interact. Mark. 2004, 28, 149165.

21. Coulter, R.; Price, L.; Feick, L. Rethinking the Origins of Involvement and Brand Commitment. J. Consum. Res. 2003, 30, 151-169. [CrossRef]

22. Ofcom. Children and Parents: Media Use and Attitudes Report. 2019. Available online: https://www.ofcom.org.uk/research-and-data/media-literacy-research/childrens/children-and-parentsmedia-use-and-attitudes-report-2019 (accessed on 4 July 2020).

23. Livingstone, S.; Helsper, E. Does advertising literacy mediate the effects of advertising on children? A critical examination of two linked research literatures in relation to obesity and food choice. J. Commun. 2006, 56, 560-584. [CrossRef]

24. Rozendaal, E.; Buijzen, M.; Valkenburg, P. Think-aloud method superior to thought-listing in increasing children's advertising defenses. Hum. Commun. Res. 2011, 38, 198-220.

25. Van Reijmersdal, E. Brand placement prominence: Good for memory! Bad for attitudes? J. Advert. Res. 2009, 49, 151-153. [CrossRef]

26. Nguyen, L.; Roedder, D. The development of self-brand connections in children and adolescents. J. Consum. Res. 2005, 32, 119-129.

27. Livingstone, S. Debating children's susceptibility to persuasion-Where does fairness come in? Int. J. Advert. 2009, 28, 170-174.

28. Rozendaal, E.; Buijzen, M.M.; Valkenburg, P. Do children's cognitive advertising defenses reduce their desire for advertised products? Communications 2009, 34, 287-303. [CrossRef]

29. Lu, J.; Hao, Q.; Jing, M. Consuming, sharing, and creating content: How young students use new social media in and outside school. Comput. Hum. Behav. 2016, 64, 55-64. [CrossRef]

30. Brodie, R.J.; Hollebeek, L.; Juric, B.; Ilic, A. customer engagement: Conceptual domain, fundamental propositions \& implications for research in service marketing. J. Serv. Res. 2011, 14, 252-271.

31. Calder, B.J.; Malthouse, E.; Schaedel, U. An experimental study of the relationship between online engagement and advertising effectiveness. J. Interact. Mark. 2009, 23, 321-331. [CrossRef]

32. Muntinga, D.; Moorman, M.; Smit, E. Introducing COBRAs. Int. J. Advert. 2011, 30, 13-46. [CrossRef]

33. Schivinski, B.; Christodoulides, G.; Dabrowski, D. Measuring consumers' engagement with brand-related social-media content: Development and validation of a scale that identifies levels of social-media engagement with brands. J. Advert. Res. 2016, 56, 64-80. [CrossRef]

34. Yoo, B.; Donthu, N. Developing and validating a multidimensional consumer-based brand equity scale. J. Bus. Res. 2001, 52, 1-14. [CrossRef]

35. Sirgy, M.J.; Grewal, D.; Mangleburg, T.F.; Park, J.; Chon, K.; Claiborne, C.B.; Johar, J.S.; Berkman, H. Assessing the predictive validity of two methods of measuring self-image congruence. J. Acad. Mark. Sci. 1997, 25, 229-241. [CrossRef]

36. Kline, R.B. Principles and Practice of Structural Equation Modeling, 4th ed.; Guilford Publications: New York, NY, USA, 2015.

37. Schermelleh-Engels, K.; Moosbrugger, H.; Müller, H. Evaluating the fit of structural equation models: Tests of significance and descriptive goodness-of-fit measures. Methods Psychol. Res. Online 2003, 8, 23-74.

38. Mahalanobis, P.C. On the Generalized Distance in Statistics. Proc. Natl. Inst. Sci. 1936, 2, 49-55.

39. Mardia, K.V. Applications of some measures of multivariate skewness and kurtosis in testing normality and robustness studies. Sankhyā Indian J. Stat. 1974, 36, 115-128.

40. Nevitt, J.; Hancock, G.R. Performance of bootstrapping approaches to model test statistics and parameter standard error estimation in structural equation modeling. Struct. Equ. Model. 2001, 8, 353-377. [CrossRef]

41. Enders, C.K. Using the expectation maximization algorithm to estimate coefficient alpha for scales with item-level missing data. Psychol. Methods 2003, 8, 322-337. [CrossRef] [PubMed] 
42. Cronbach, L.J. Coefficient alpha and the internal structure of tests. Psychometrika 1951, 16, 297-334. [CrossRef]

43. Hair, J.F.; Black, W.C.; Babin, B.J.; Anderson, R.E.; Tatham, R.L. Multivariate Data Analysis, 6th ed.; Pearson Education Inc.: Upper Saddle River, NJ, USA, 2006.

44. Fornell, C.; Larcker, D.F. Evaluating structural equation models with unobservable variable and measurement error. J. Mark. Res. 1981, 18, 39-50. [CrossRef]

45. Hooper, D.; Coughlan, J.; Mullen, M. Structural equation modeling: Guidelines for determining model fit. Electron. J. Bus. Res. Methods 2008, 6, 53-60.

46. Kenny, D.A. Measuring Model Fit. 2020. Available online: http://davidakenny.net/cm/fit.htm (accessed on 7 June 2020).

47. Steiger, J.H. Understanding the limitations of global fit assessment in structural equation modeling. Personal. Individ. Differ. 2007, 42, 893-898. [CrossRef]

48. Henseler, J.; Ringle, C.M.; Sarstedt, M. A New Criterion for Assessing Discriminant Validity in Variance-based Structural Equation Modeling. J. Acad. Mark. Sci. 2015, 43, 115-135. [CrossRef]

49. Hui, B.S.; Wold, H. Consistency and consistency at large of partial least squares estimates. Syst. Indirect Obs. 1982, 2, 119-130.

50. Kline, R. Convergence of structural equation modeling and multilevel modeling. In The SAGE Handbook of Innovation in Social Research Methods; Williams, M., Vogt, W.P., Eds.; SAGE Publications Ltd: London, UK, 2011; pp. 562-589. [CrossRef]

51. Teo, T.; Tsai, L.T.; Yang, C.C. Applying structural equation modeling (SEM) in educational research. In Application of Structural Equation Modeling in Educational Research and Practice. Contemporary Approaches to Research in Learning Innovations; Khine, M.S., Ed.; Sense Publishers: Rotterdam, The Netherlands, 2013. [CrossRef]

52. Montgomery, K.; Chester, J. Interactive food and beverage marketing: Targeting adolescents in the digital age. J. Adolesc. Health 2009, 45, 18-29. [CrossRef]

53. Boyland, E.J.; Whalen, R. Food advertising to children and its effects on diet: Review of recent prevalence and impact data. Pediatr. Diabetes 2015, 16, 331-337. [CrossRef] [PubMed]

54. Livingstone, S.; Haddon, L. Kids online: Opportunities and Risks for Children; Bristol University Press: Bristol, UK, 2009. [CrossRef]

55. Tufte, B. Children, media and consumption. Young Consum. 2004, 5, 69-76. [CrossRef]

56. Hook, M.; Baxter, S.; Kulczynski, A. Children's participation in brand-based social networks: Examining the role of evaluative social identity, self-esteem and anticipated emotions on commitment and desire to recommend. Int. J. Consum. Stud. 2016, 40, 552-561. [CrossRef]

57. Schivinski, B.; Dabrowski, D. The impact of brand communication on brand equity through Facebook. J. Res. Interact. Mark. 2015, 9, 31-53. [CrossRef]

58. Labrecque, L.I. Fostering consumer-brand relationships in social media environments: The role of parasocial interaction. J. Interact. Mark. 2014, 28, 134-148. [CrossRef]

59. Jaffit, D. Marketing to Millennials. Available online: http://www.bizcommunity.com/Article/196/423/127 (accessed on 20 June 2020).

60. Pombo, A. Youth Marketers, "Here's Why Traditional Advertising Doesn't Cut it Anymore". Available online: http://www.bizcommunity.com/Article/196/347/127714.html (accessed on 20 July 2019).

Publisher's Note: MDPI stays neutral with regard to jurisdictional claims in published maps and institutional affiliations.

(C) 2020 by the authors. Licensee MDPI, Basel, Switzerland. This article is an open access article distributed under the terms and conditions of the Creative Commons Attribution (CC BY) license (http://creativecommons.org/licenses/by/4.0/). 